\title{
EDITORIAL
}

\section{Science Research in India at Cross-roads}

Science research in India has made significant progress in recent decades, and this has placed the country in the reckoning, although currently not at the desired high level, but as a potential leader of the future. While looking forward to being in the lead, we need to examine the current models of research publication practices, policies of funding agencies and social considerations, which may facilitate or derail the path to leadership.

Contemporary policies that have influenced the nature and funding of science research in India have generally followed, directly or indirectly, the paradigms developed and practiced in western hemisphere. However, in the west itself increasing concerns are being raised that multiple factors threaten the pleasure and philosophy of science research, which is expected to be primarily directed to understand nature of the unknown.

The damaging effect of the various metrics that define and quantify the quality or "impact" of research activities as revealed through scientific publications has been very widely discussed and recognized. Without repeating the causes and consequences of such "quantification" of research contributions, it suffices to re-emphasize that serious damage is being inflicted on a large number of upcoming scientists of the country who get trapped into the vicious cycle of "publish or perish". Everyone agrees that the damaging impact of the "impact factor" (and similar other metrics) can be minimized only if the working scientists, especially those already established and, therefore, often sitting in the "judgment seat", change their mindset. Are we really making any serious efforts in this direction?

The paradigms that regulate research funding have undergone significant changes in recent decades. In most countries, including in India, more governmental funds are available for research. However, the increased funding has been offset, especially in the more "advanced" countries like the US, by the priorities and policies being followed for supporting research. The cost of research has gone up because of the general inflation but also because of the increasing cost of technology and "kits". At the same time, there are more aspirants seking benefit from the available funding. This has resulted in severe, and often unhealthy competition for "grabbing" the grant. A greater worry, however, comes from the nature of research that is considered worthy of being fundable, especially in advanced countries. More scientists are involved, across the world, in bio-medical research so that a substantial share of extra-mural governmental funding gets channeled in this area. Fuelled by the dramatic emergence of bio- and other technologies, there has been, over the years, ever-increasing emphasis on "deliverables" with applied value. A greater value addition to a university's ranking through industrial collaborations also signals more emphasis on applied research.

Demand for achieving higher numerical "impact" value, tough competition and emphasis on "applied research", while taking away the real pleasure of discovery, have placed the younger researchers at a great disadvantage. In a recent analysis, Alberts et al. (2015) show that the NIH (USA)-funded RO1 grants have undergone a complete reversal in terms of beneficiary age groups: according to their data, there were nearly 40 times more 36 years or younger scientists than 66 years or older in 1980 who received the RO1 grants; however, this trend gradually changed so that in 2002, the proportion of older scientists began to increase and in 2010, the number of older scientists who received the RO1 grants was nearly 2.5 times that of the younger ones. This is indeed alarming.

Perhaps this trend may not be as worrisome in India, partly because of our system of "retirement", 
so that most of those in the older age group do not continue, voluntarily or involuntarily, as active researchers. In addition, several avenues that specifically fund younger age groups have been put in place. However, the trend to engage in "applied" research, especially in the bio-medical field, is increasing: most of the young investigators' projects, be it for the various post-doctoral fellowships, young scientists projects or for the INSPIRE Faculty fellowships are directed to application-oriented issues, like drug-discovery, developing more efficient therapeutics or delivering them more efficiently, or developing agriculturally important transgenics. If many of such research efforts indeed succeed, the country should be free of most diseases in the next few years. Alas, this would not happen because the investigators who seriously wish to cure the disease may not often know the basics of such strategies and/ or may have little or no basic data on the causatives that prevail in our populations. This would require basic research.

Although most of the funding agencies in India have not yet officially put a premium on applied research, the PIs are often asked to justify. Political wisdom also encourages politicians to talk about the need for research that would alleviate poverty, disease, pollution and the like. The trends in research and popular press publications also encourage the young scientists to work in areas that are "fashionable" in the west. Basic research typically provides incremental advances in small steps while applied research has greater chance of attracting attention of the scientific community and of the general population. Consequently, there is indirect pressure on promoting the increasingly common perception that applied research is preferred, and therefore, more likely to be funded and recognized.

The administration of funding for science research is another source of concern in the country. Year-after-year, the politicians and, therefore, governmental agencies, bring cheers to researchers by promising greater allocation for higher education and research. We are also promised speedy processing of research proposals and quick release of the approved grants to minimize our worries and maximize our productivity. However, as each of us who write research projects and keep on waiting for the much sought-after sanction letter and subsequently the funds, knows very well the recurrent cheers floated by various agencies remain "virtual"! The processing of projects continues to move at slow pace and even when it moves, the final straw is that the budget has been cut or not released to the agency and therefore, we need to wait for an uncertain period of time. This state of affairs indeed has serious and damaging consequences.

An additional source of worry in the context of scientific research in the country is promotion of "pseudo-science" in some quarters. The guest editorial by Dr. R. Narsimha and two letters by Drs. T. V. Ramakrishnan and D. Balasubramanian in this issue (co-published with Current Science) highlight the negative impact of such "pseudo-science".

Are we preparing ourselves to take up these issues and discuss long-term remedial measures which would indeed harness the enormous youth power to push the country to a state of leadership? The science academies/societies and science administrators need to come out of their comfort zones and initiate serious and proactive steps that can help the country to choose the right path. Perhaps those established, may not often like or wish to change the state of inertia. It is the younger generation which has much at stake and, therefore, needs to break the vicious circle. In this context, the launch of the Indian National Young Academy of Sciences (INYAS) should be a new and effective catalyst that can make good use of the energetic young scientists to charter the right direction. Best wishes to them.

\section{References}

Alberts B, Kirschner M W, Tilghman S C, Varmus H (2015) Addressing systemic problems in the biomedical research enterprise Proc Natl Acad Sci USA (112: 1912-1913).

Balasubramanian D (2015) Good fences make good neighbours Proc Indian Natn Sci Acad 81343.

Narsimha R (2015) The 'historic' storm at the Mumbai Science Congress Proc Indian Natn Sci Acad 81 339-341.

Ramakrishnan T V (2015) Early workings and modern science: some reactions to current happenings Proc Indian Natn Sci Acad $\mathbf{8 1} 345$.

S C Lakhotia Editor-in-Chief 